\title{
Advanced Test Setup for Accelerated Aging of Plastics by Visible LED Radiation
}

\author{
Moritz Hemmerich ${ }^{1,2, * \mathbb{C}}$, Jörg Meyer ${ }^{1}(\mathbb{D})$ and Frank Walther ${ }^{3}(\mathbb{C})$ \\ 1 Photonics and Materials Science, Hamm-Lippstadt University of Applied Sciences, Marker Allee 76-78, \\ 59063 Hamm, Germany; joerg.meyer@hshl.de \\ 2 L-LAB, Research Institute for Automotive Lighting and Mechatronics, Rixbecker Str. 75, \\ 59552 Lippstadt, Germany \\ 3 Department of Materials Test Engineering, TU Dortmund University, Baroper Str. 303, \\ 44227 Dortmund, Germany; frank.walther@tu-dortmund.de \\ * Correspondence: moritz.hemmerich@hshl.de
}

Received: 20 August 2020; Accepted: 22 September 2020; Published: 24 September 2020

\begin{abstract}
In this article, a newly developed test setup for the aging of optical plastics by visible radiation $(450 \mathrm{~nm})$ is presented. In addition to a comprehensive monitoring of the operating parameters and an efficient cooling of the high-power multiple chips on board the LEDs used, the plastic samples can be fully temperature-controlled, independent of the radiant power of the LED, due to fluid driven thermostatization. The sample surface temperatures and irradiance values were verified by in situ measurements and simulations. To validate the test setup, polycarbonate samples with well-known aging behavior were aged for $1896 \mathrm{~h}$. By spectroscopic IR and UV/vis analysis of the samples at different aging times, known optical aging results of polycarbonate could be observed, which proves the intended operationality of the system.
\end{abstract}

Keywords: advanced irradiation setup; photodegradation; blue light; LED; polycarbonate; accelerated aging; optical materials

\section{Introduction}

The market share of LEDs in lighting applications has increased rapidly. In 2014, LEDs made up less than $4 \%$ of the total lumen-hours in lighting. For 2023, a percentage of around $84 \%$ is predicted [1]. The advantages of LEDs over conventional light sources are their long operational lifetime (more than $15,000 \mathrm{~h}$ on average), high luminous efficacy, and the possibility of compact design and simple installation [2-5]. However, this poses problems for the stability of the optical plastic components, such as lenses, cover lenses, or housing, which are installed close to the LED. Two of the most commonly used transparent plastics in the field of lighting applications are polycarbonate (PC) and poly(methyl methacrylate) (PMMA) [6]. Due to ever more compact designs, such as high-resolution LED matrix headlights [7] or light guides with very small light-emitting surfaces, plastic components associated with LED lighting are exposed to increasing levels of visible radiation. The coating of a blue emitting diode chip with a luminescent color converter is the most commonly used industrial technology to produce a white LED [8,9]. Even after partial down-conversion, these LEDs still contain a high proportion of high-energy blue radiation that can drive the degradation of plastics. To better assess and more accurately predict the stability of optical plastics in LED applications, it is crucial to develop a suitable test setup, which gives valid and reproducible accelerated results on the aging behavior. Since real-time aging takes too long, the common procedure is to expose the samples to irradiation that is several times higher than in reality. This allows the degradation behavior to be simulated on suitable time scales and thus to be predicted. [10] The degradation behavior of various plastics, 
e.g., PC [11-14], PMMA [15], and PE [16], under UV-irradiation has been investigated in several studies. In these investigations, mostly commercial aging setups based on xenon arc lamps manufactured by ATLAS $^{\text {TM }}$ were used. Both purely thermal- [17-19] and photodegradation by blue light [20-26] of bispenol A PC were investigated by Mehr et al. For the experiments, a self-made apparatus was used, in which samples are heated simultaneously by a hot plate and irradiated by several LEDs. Sikora et al. investigated the effects of pulsed UV and white light irradiation on PMMA. For this purpose, a setup was used in which a single sample was irradiated at several locations with different wavelengths and pulse widths [15]. Gandhi et al. also investigated the accelerated aging of PC by a blue emitting LED, whereby the focus of the work was on the determination of acceleration parameters in order to be able to make service life predictions [27]. The experiments were performed in a commercial test device called "Elevated Temperature Irradiance Chamber" (ETIC), in which the samples are irradiated via a lightguide in a fan temperature-controlled test chamber. To the best of our knowledge, this test equipment is no longer commercially available.

All these investigations provided interesting findings to better understand and predict the aging behavior of PC and PMMA. To be able to carry out further and more in-depth aging studies on different optical plastics in the future, we developed a new test setup termed "Monitored Liquid Thermostatted Irradiation Setup" (MLTIS) for accelerated aging with blue light. This test setup has been designed considering experience with the test setups presented above and has been improved with regard to accuracy, handling, and scalability.

The most important features of the MLTIS are briefly explained below:

- The sample chamber is thermostatted by the circulation of a liquid, which enables a temperature control of the sample independent of the radiant power of the LED.

- All operating parameters of the experimental setup are measured or simulated in advance.

- The specimens are aged separately from each other in individual chambers, which avoids mutual influence of the samples during aging.

- The chamber geometry can theoretically be replaced at will by other geometries, so that samples of different shapes and sizes can be tested.

- The LED and sample temperature as well as the irradiation on the sample surface are monitored during the entire test duration.

- An independent design of the MLTIS enables massive parallelization by using further chambers.

A detailed description of the MLTIS' design and functionality is given in the next section. To demonstrate the functionality of the described test setup, first aging experiments were carried out using exemplary PC samples, due to the well-described aging phenomena that occur with such samples. The samples were exposed to both optical and thermal stress to induce photo-thermal degradation effects. The PC samples were analyzed by ATR-FTIR and UV/vis spectroscopy.

\section{Materials and Methods}

\subsection{Experimental Setup}

\subsubsection{Design of the "Monitored Liquid Thermostatted Irradiation Setup" (MLTIS)}

The basic design of the MLTIS is shown schematically in Figure 1a. The central part of the MLTIS is the double-walled stainless-steel sample chamber. The chamber is continuously thermostatted by the circulation of a liquid. By suitable selection of the liquid, the used circulating thermostat can realize temperatures ranging from -10 to $140{ }^{\circ} \mathrm{C}$, whereby the upper temperature limit is currently $120^{\circ} \mathrm{C}$ due to the gaskets used and the liquid medium, viz. water. 


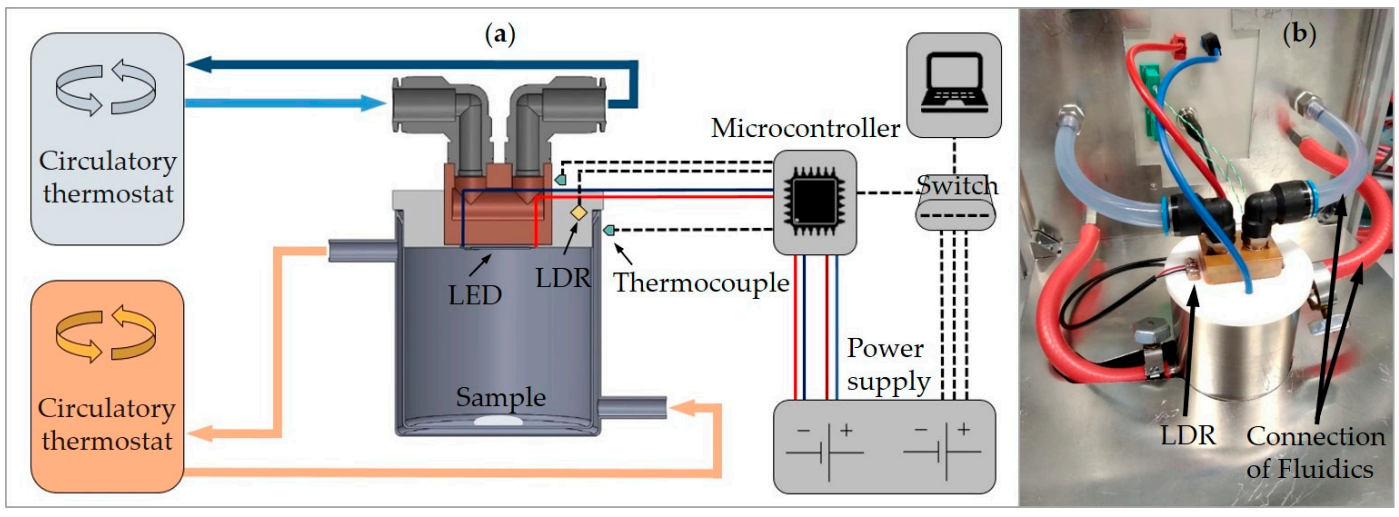

Figure 1. Design of the MLTIS: (a) schematic representation; and (b) photo of an aging unit with corresponding sensors, electrical, and fluidic connections. The two green thermocouples are mounted on the backside of the copper block and the sample chamber.

The high-power LED used for aging is positioned above the sample. To ensure a long service lifetime and high efficiency, the LED is mounted heat-conductingly on a copper block, which is water-cooled by a further circulating thermostat. The water temperature is $34{ }^{\circ} \mathrm{C}$, which ensures a constant cathode temperature of the LED of $50^{\circ} \mathrm{C}$ throughout the experiment's duration. The copper block, in turn, is embedded in a PTFE cover which is placed on the sample vessel. Each sample chamber is equipped with three sensors: two thermocouples (type-K, RS Components, Frankfurt am Main, Germany) and one photo resistor (hereafter abbreviated as LDR, LDR-KY-018, Joy-IT, Neukirchen-Vluyn, Germany). The first thermocouple measures the temperature of the outer wall of the sample chamber, which corresponds by a rough approximation to the temperature of the sample. The second thermocouple is located on the copper block for an indirect measurement of the cathode temperature of the LED. The LDR is embedded in an indentation in the PTFE cover and is used for indirect determination of the irradiance on the bottom of the sample chamber (Figure 1b). The sensor data of each sample chamber are sent separately to a microcontroller for further processing. Afterwards, the data from each sample chamber are transmitted from an attached Ethernet board via a local network to a central processing unit. The power supply for the LED is provided by a $750 \mathrm{~W}$ constant current power supply (Genesys 750W, TDK-Lambda, Tokyo, Japan) whose operating parameters are also sent to the central computing unit via Ethernet. The three sensor values of all running sample chambers are retrieved sequentially via the corresponding IP addresses by a MATLAB (R2018b) script. The query time can be chosen as desired.

By monitoring (Figure 2b) and recording all operating conditions, a controlled and traceable aging can be ensured for each sample chamber individually. In the case of irregularities, an error $\log$ is created, and the system of the corresponding sample chamber is shut down. To achieve a higher throughput and better comparability of the experiments, twelve sample chambers can currently be operated simultaneously. As shown in Figure 2a, the reactors are operated in radiation-proof enclosures for eye-protection. For inspection during the experiment, the sample chambers can be observed through a small window, which strongly attenuates the blue radiation. The upper part of the enclosure can be removed for sample handling and experiment setup. 

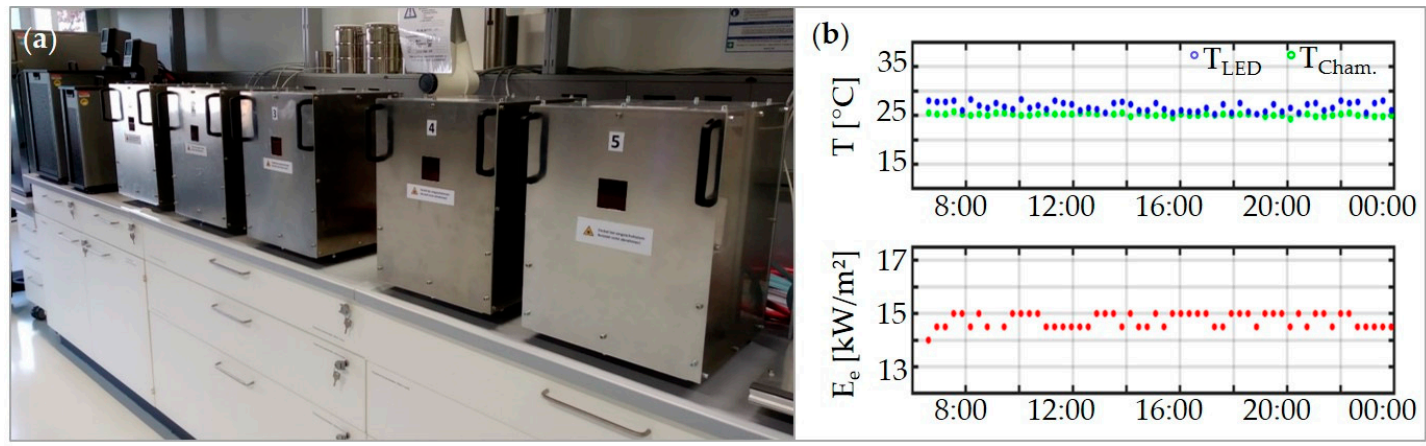

Figure 2. (a) Photograph of the enclosures for radiation-protection; and (b) exemplary presentation of the MATLAB Plot-Window, showing the temperatures of sample chamber and copper block (top) and the calculated irradiance (from LDR-readouts) on the bottom of the sample chamber (bottom) over a time period of $18 \mathrm{~h}$.

\subsubsection{Sample Chamber}

The purpose-built double-walled cylindrical stainless-steel sample chamber described in this work has an inner diameter of $68 \mathrm{~mm}$ and a height of $80 \mathrm{~mm}$. The inner side of the stainless-steel chamber has a reflectivity of $51.9 \%$ at $450 \mathrm{~nm}$. The LED is located at a distance of $65 \mathrm{~mm}$ above the sample. A further sample chamber with a diameter of $100 \mathrm{~mm}$ and a height of $156 \mathrm{~mm}$ (TSS-G $1000 \mathrm{~W}$, KGW-Isotherm, Karlsruhe, Germany) is available for the aging of larger samples. Further sample chamber geometries can be realized if required.

\subsubsection{Multiple Chips on Board LED}

Blue high-power multiple chips on board (MCOB) LEDs (CLU048-1818C4-B455-XX, Citizen Electronics, Kamikurechi, Japan) were used to age the samples. The LEDs have a narrow band spectrum with a full width at half maximum (FWHM) of $17 \mathrm{~nm}$ and a peak wavelength of $450 \mathrm{~nm}$. The maximum electrical power consumption is $202 \mathrm{~W}$. The special feature of the LED is its long service life, which has been proven in real-time tests by the manufacturer. To determine the spectral power distribution, the LED module was measured at a constant cathode temperature of $50{ }^{\circ} \mathrm{C}$ in an integrating sphere (IS 3900, Optronic Laboratories, Orlando, FL, USA). The current was varied in $10 \%$ steps from $0.486(30 \%)$ to $3.24 \mathrm{~A}(200 \%)$, referring to the typical current of $1.62 \mathrm{~A}(100 \%)$, given in the data sheet. To increase the service life, the LED is normally operated at $1.134 \mathrm{~A}(70 \%)$ during aging tests.

\subsubsection{Irradiance Simulation}

No equipment for optical measurements was available to determine the irradiance at the bottom of the sample chamber, due to the high optical power of the LED which would saturate or even destroy unfit sensors (e.g., those housed in colored plastics). For this reason, a photometric raytracing simulation was used. The optical parameters of the LED, the optical properties of all irradiated materials, and the geometry were determined. The optical parameters of the LED were taken from the integration sphere measurements as described above. The reflectivity of the stainless steel and PTFE parts, which are exposed to the radiation, were determined using a smaller integration sphere (ISR-2600, Shimadzu, Kyoto, Japan). The geometry was represented as a CAD model. The simulation was carried out with an in-house raytracing simulation software for optical applications. Figure 3 shows the simulation setup using a ray that is reflected 50 times. After 50 reflections, the simulation was interrupted for the respective ray, since the remaining energy is less than $10 \mathrm{ppt}$. In total, each simulation was performed with 5 million rays. 


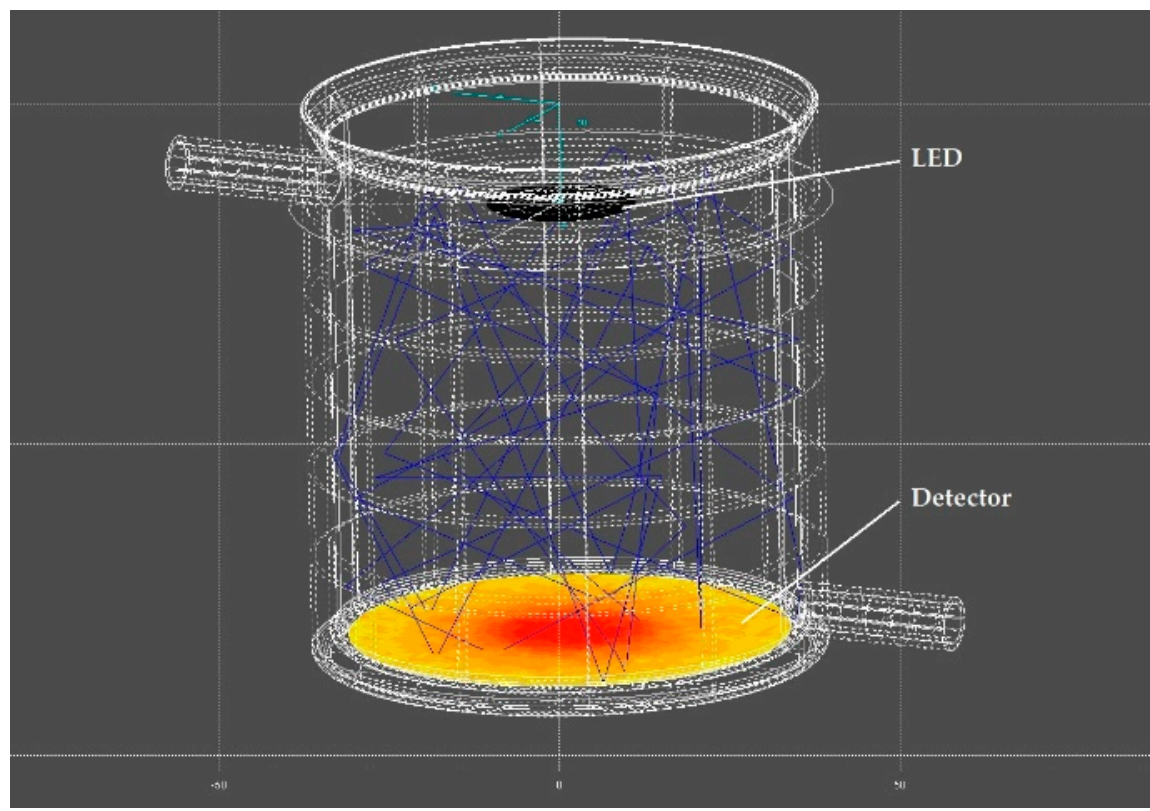

Figure 3. Representation of the raytracing setup with a beam reflected 50 times. The detector visualizes the irradiance in false colors.

\subsubsection{Sample Temperature Measurement}

To ensure that the sample temperature can be controlled independently of the radiant power of the LED, the sample temperatures have been determined as a function of the set temperature of the thermostat. A direct measurement of the sample temperature with a thermocouple, with the LED driven at the desired 70\% nominal current, was not expedient, because the thermocouple absorbs a high amount of radiation and therefore does not provide reliable temperature values for transparent samples. For this reason, an infrared (IR) camera (VarioCAM HR, Infratec, Dresden, Germany) was positioned statically above the sample chamber. After a period of $30 \mathrm{~min}$, during which temperature equilibration was achieved, the LED was switched off, the cover of the chamber was removed, and a thermal image of the PC sample surface was taken immediately. The temperature values of three independent measurements of the sample surface were averaged afterwards. This process was performed for nominal temperatures of $10-90{ }^{\circ} \mathrm{C}$ in $10{ }^{\circ} \mathrm{C}$ increments.

\subsection{Aging and Analysis Methods}

\subsubsection{Sample Geometry and Aging Conditions}

Polycarbonate granulate (Tarflon LC 1500, Idemitsu Kosan, Tokyo, Japan) was injection molded into disks with a diameter of $20 \mathrm{~mm}$ and a height of $1.5 \mathrm{~mm}$. Injection molding was carried out with a lab scale instrument (Minijet Pro, Thermo Fisher Scientific, Waltham, MA, USA). Cylinder temperature, mold temperature, and injection and post pressure were varied in advance to achieve the highest possible transparency of the samples in the wavelength range from 300 to $800 \mathrm{~nm}$. The best results were achieved at a cylinder temperature of $85^{\circ} \mathrm{C}$, a mold temperature of $255^{\circ} \mathrm{C}$, an injection pressure of 800 bar, and a post pressure of 560 bar. Seventeen sample disks, produced using these parameters, were selected for aging. Due to the high number of samples, the effects of measurement or material errors for individual measurements or samples can be minimized.

Since only two sample chambers were available at the start of the experimental series, one sample each was positioned centrally in the chamber. The remaining samples were positioned around them. Additionally, to speed up the aging process, the distance between the samples and the LED was reduced to $18 \mathrm{~mm}$. The maximum irradiance $E_{2}$ at any distance $d_{2}$ from the LED can be approximated 
as a function of a known irradiance $E_{1}$ at a certain distance $d_{1}$, according to the photometric distance law [5] (Equation (1)).

$$
E_{2}=\frac{E_{1} \cdot d_{1}^{2}}{d_{2}^{2}}
$$

Depending on the calculated maximum irradiance in the center, the irradiance drop to the peripheral areas $E(\alpha)$ can be estimated as a function of the angle $\alpha$, between the center and an arbitrary point, according to the $\cos ^{4}$-Law (Equation (2)).

$$
E(\alpha)=E_{2} \cdot \cos ^{4}(\alpha)
$$

The samples at the edges were aged for $1896 \mathrm{~h}$ in total. UV/vis and FTIR analyses were carried out both before aging and after each of 24 successive aging periods.

\subsubsection{FTIR-Spectroscopy}

Infrared spectra were obtained with the infrared spectrometer (Nicolet iS50, Thermo Fisher Scientific, Waltham, MA, USA) in the mid-IR range from 4000 to $400 \mathrm{~cm}^{-1}$ in attenuated total reflection mode (ATR). Twenty scans were averaged at a resolution of $4 \mathrm{~cm}^{-1}$. For better comparability of the spectra recorded at different aging times, the spectra of all samples were normalized at $1014 \mathrm{~cm}^{-1}$ by a custom LabTalk algorithm, since no changes occur at this wavenumber. In addition, the spectra were baseline corrected at 23 positions. The exact positions of the baseline corrections are shown in Table A1 of the Appendix. To ensure that measurements are always taken at the same point on the sample, a dedicated 3D-printed sample-holder was used, which is placed on the measuring surface of the infrared spectrometer and ensures that the samples are in the same position for each measurement.

\subsubsection{UV/vis-Spectroscopy}

UV/vis measurements were performed with the UV/vis spectrometer (UV-2600, Shimadzu, Kyoto, Japan). The transmission of the aged samples at different times was performed in the range of 200-800 nm with a resolution of $1 \mathrm{~nm}$, at medium scan speed. An integrating sphere (ISR-2600, Shimadzu, Kyoto, Japan) was attached to the spectrometer to determine reflectivity where needed. From the transmission spectra of the aged samples, a calculation according to Equation (3), as defined by DIN 6167 [28], was performed to determine the yellowness index $(Y I)$ for a standard $2^{\circ}$ observer and standard illuminant $C$.

$$
Y I=100 \times \frac{1.277 \cdot X-1.059 \cdot Z}{Y}
$$

where $X, Y$, and $Z$ are the tristimulus values of the samples.

\section{Results}

\subsection{Characterization of the Experimental Setup}

\subsubsection{LED Radiant Flux and Spectrum}

Figure 4 shows the spectrum of the LED used at currents ranging from 0.486 to $3.24 \mathrm{~A}$. At the currents measured, the FWHM ranges between 15.4 and $19.4 \mathrm{~nm}$. At a current of $1.134 \mathrm{~A}$, the FWHM is $16.3 \mathrm{~nm}$. The peak wavelength is constant at $450 \mathrm{~nm}$. The radiant flux $\phi_{e}$ values calculated by integrating the spectra are shown in Figure 5. In addition, the corresponding luminous flux $\phi_{\mathrm{v}}$ values are shown. An approximately linear relationship can be observed between the current and the radiant flux as well as the luminous flux. A radiant flux of $35.79 \mathrm{~W}$ is obtained for the experimentally used operating conditions of $1.134 \mathrm{~A}$ and $50.9 \mathrm{~V}$. 


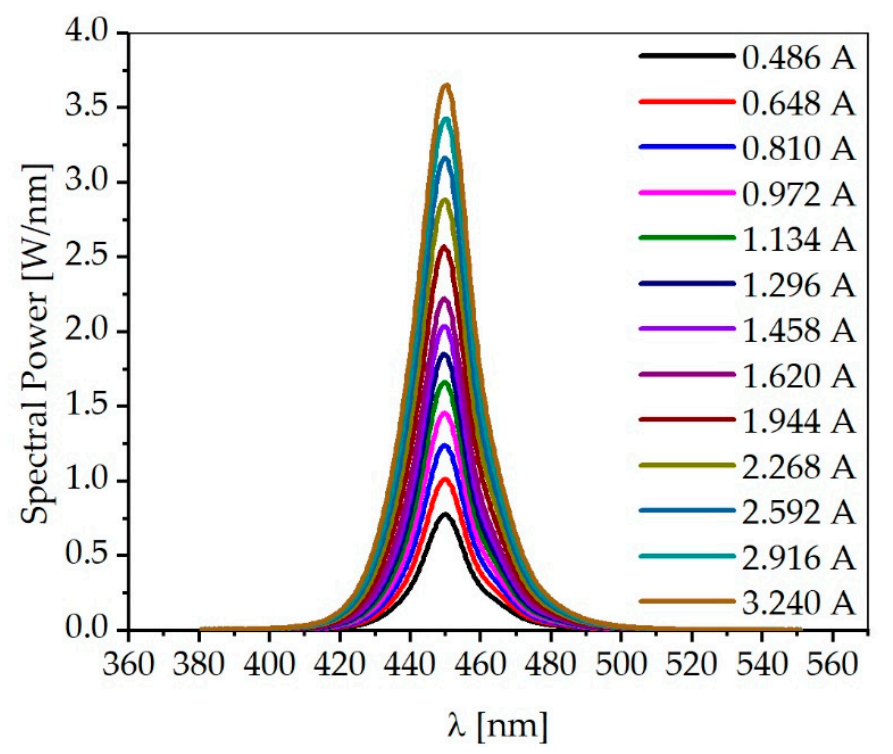

Figure 4. Spectra of the blue high-power LED used for different driving currents between 0.486 and $3.240 \mathrm{~A}$.

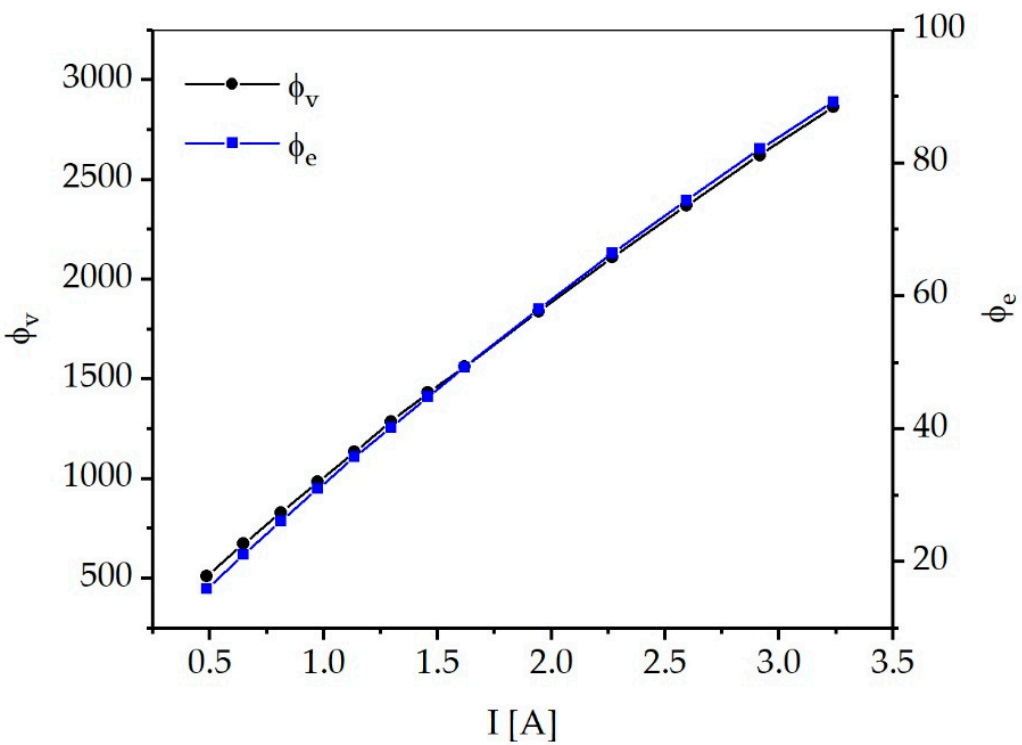

Figure 5. Radiant $\left(\phi_{\mathrm{e}}\right)$ and luminous flux $\left(\phi_{\mathrm{v}}\right)$ values for different currents between 0.486 and $3.240 \mathrm{~A}$.

This corresponds to an efficiency of $62 \%$ for the conversion of electrical power into optical power, which indicates an efficient mode of operation of the LED. Table 1 shows the remaining radiant flux and luminous flux values as a function of the current. It can be observed that the efficiency decreases with increasing current. Therefore, the preferred operation at $70 \%$ of the electrical power constitutes a good compromise between high optical power and economical operation of the LED. Figure A1 in the Appendix shows the spectrum of the LED depending on the set temperature of the thermostat used for LED cooling. 
Table 1. Luminous flux, radiant flux, and efficiency of the high-power LED used as a function of the current.

\begin{tabular}{cccc}
\hline Current I (A) & Luminous Flux $\phi_{\mathbf{v}}(\mathbf{l m})$ & Radiant Flux $\phi_{\mathbf{e}}(\mathbf{W})$ & Efficiency $\eta \mathbf{~ ( \% )}$ \\
\hline 0.486 & 512 & 15.96 & 67.3 \\
0.648 & 674 & 21.09 & 65.9 \\
0.810 & 831 & 26.17 & 64.7 \\
0.972 & 983 & 30.98 & 63.2 \\
1.134 & 1135 & 35.79 & 62.0 \\
1.296 & 1287 & 40.24 & 60.5 \\
1.458 & 1431 & 44.84 & 59.4 \\
1.620 & 1563 & 49.27 & 58.3 \\
1.944 & 1841 & 58.05 & 56.3 \\
2.268 & 2110 & 66.48 & 54.5 \\
2.592 & 2370 & 74.42 & 52.7 \\
2.916 & 2624 & 82.15 & 51.1 \\
3.240 & 2866 & 89.25 & 49.5 \\
\hline
\end{tabular}

\subsubsection{Degree of Irradiance at the Sample Level}

As mentioned above, the irradiance on the bottom of the sample chamber was simulated by photometric raytracing. Figure 6 shows an exemplary result of a simulation in which the position-dependent irradiance level is displayed in false colors. The highest irradiance results in the center. From there outward, the irradiance decreases. The total irradiance is radially symmetrically distributed.

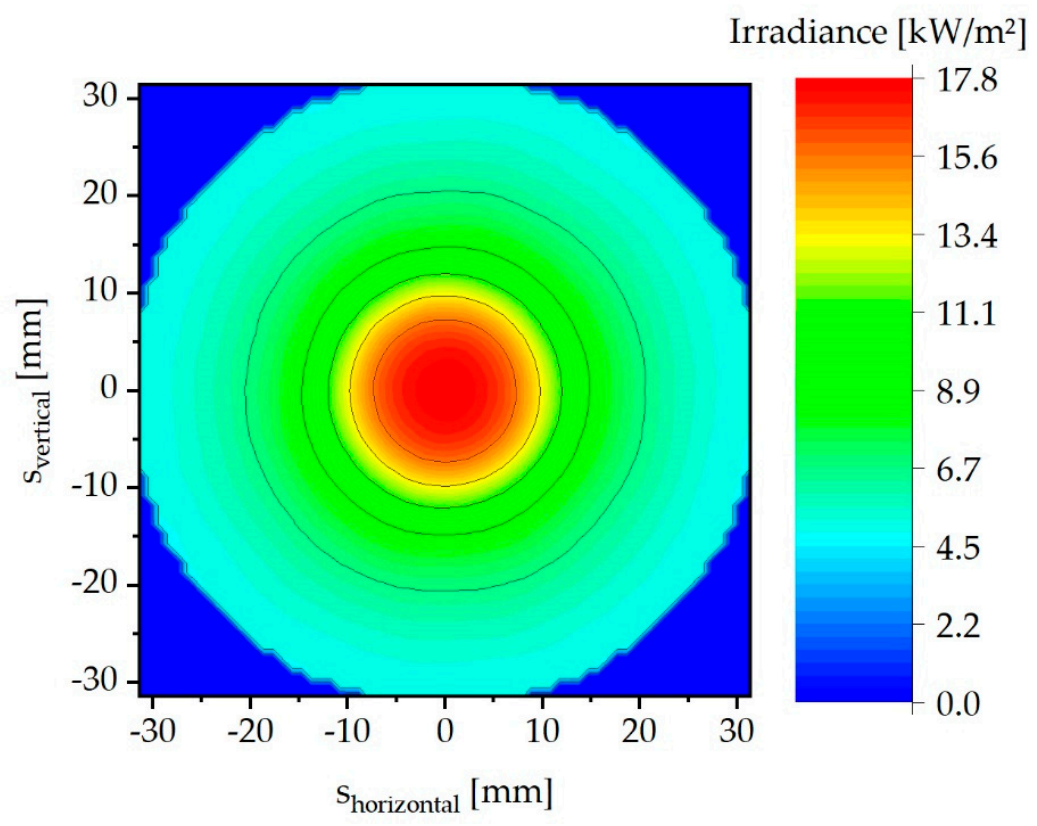

Figure 6. Exemplary irradiance distribution on the sample chamber ground in false colors at a current of $1.296 \mathrm{~A}$.

For better illustration, the resulting irradiances for different currents are shown in vertical cross-sections in Figure 7. The area marked by the dashed lines has a size of $20 \mathrm{~mm}$ and thus indicates the area in which the round sample disk would be located. In the marked area, $51 \%$ of the total optical power is incident. In relation to the total irradiance, the decrease in the marked area is about $35 \%$. 


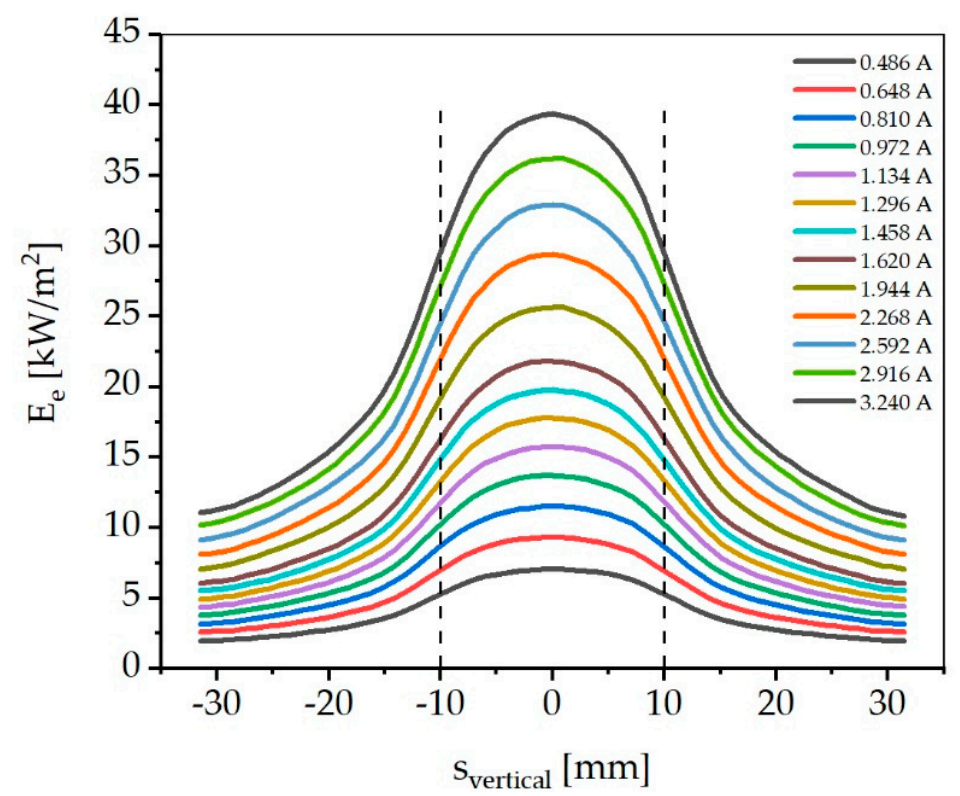

Figure 7. Vertical sections through the irradiance distribution on the virtual detector of the raytracing simulation. The area between the dashed lines marks the position of a centered sample.

Figure 8 shows the mean irradiance in the sample area for different operating currents. The fitting function used shows a linear relationship between the current and the mean irradiance, whereby the irradiance increases by about $10.7 \mathrm{~kW} / \mathrm{m}^{2}$ per ampere. The typical current of $1.134 \mathrm{~A}$ results in an average irradiance of $14.4 \mathrm{~kW} / \mathrm{m}^{2}$. We are aware of the fact that the presented graph in Figure 8 must typically pass through the origin and that there will be a flattening of the curve for larger currents. However, to fit the data between the highest and lowest measured value, a linear function with a positive y-axis section was deliberately chosen, as this approximates the existing data points in an uncomplicated and very accurate way. This allows irradiances to be calculated precisely within the available current range.

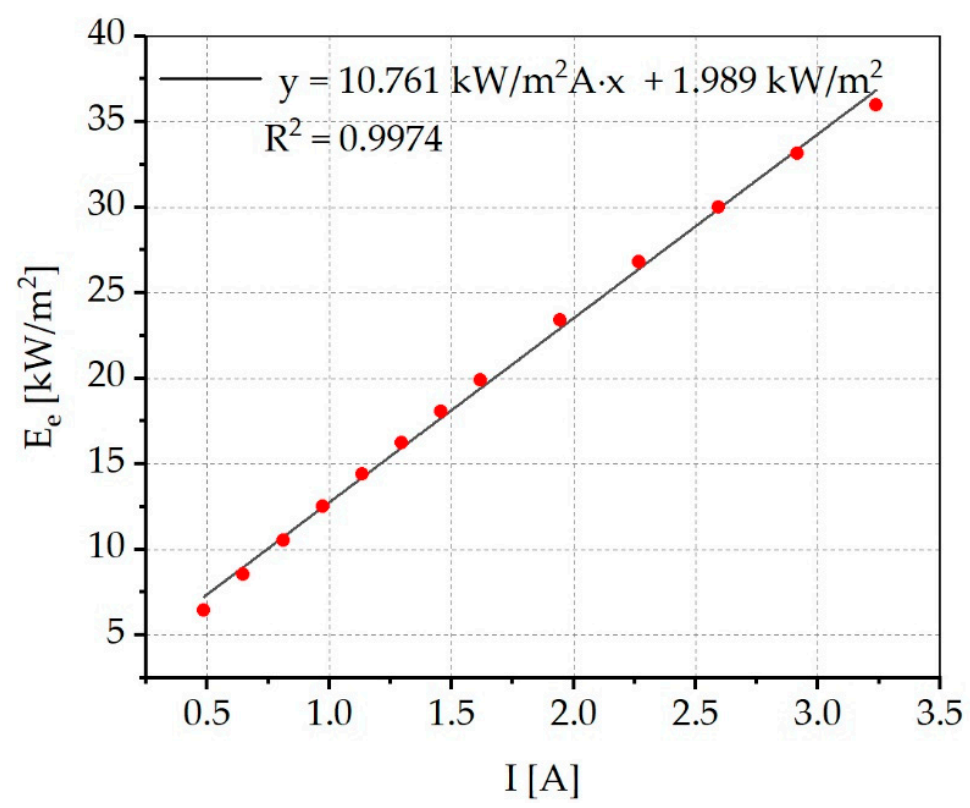

Figure 8. Mean irradiance in the sample area for different currents. The irradiance increases by about $10.7 \mathrm{~kW} / \mathrm{m}^{2}$ per ampere. 


\subsubsection{Sample Temperature}

Figure 9 shows the results of the sample surface temperature measurement using an IR camera. These measurements were carried out at the typical current of $1.134 \mathrm{~A}$ and a resulting irradiance of $14.4 \mathrm{~kW} / \mathrm{m}^{2}$. The results indicate that, for the measured temperature range, any sample temperature can be achieved, independent of the radiant power, if the samples do not interact strongly with the impinging radiation (i.e., optically transparent samples). Due to the linear relationship between the temperatures set at the thermostat and the sample surface temperature, it can be assumed that sample temperatures $<10^{\circ} \mathrm{C}$ and $>90^{\circ} \mathrm{C}$ can be achieved. The thermostat temperature required to reach a selected sample surface temperature can be determined in advance based on the measurement data and the fitting function of these data. Basically, the sample surface temperature increases by $0.91{ }^{\circ} \mathrm{C}$ when the thermostat temperature is increased by $1^{\circ} \mathrm{C}$. By increasing the irradiance, either by increasing the current or by decreasing the distance between the LED and the sample, the sample temperature, at the same thermostat temperature, will also increase. It can be assumed that the function will remain linear due to the efficient temperature control.

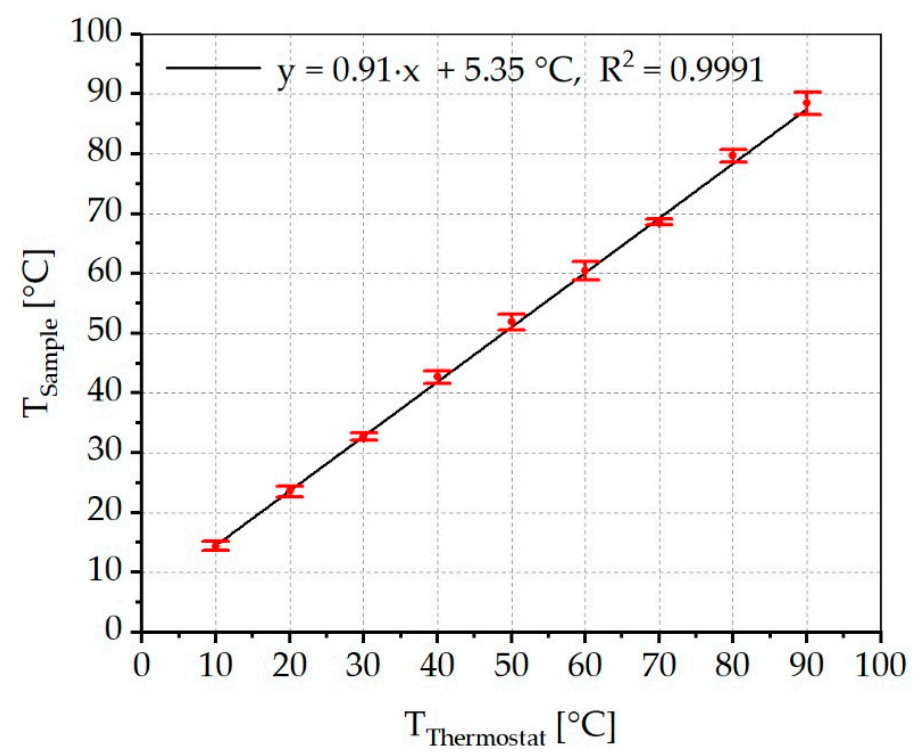

Figure 9. Sample surface temperature as function of the set thermostat temperature. The sample surface temperature increases by $0.91^{\circ} \mathrm{C}$ per $1^{\circ} \mathrm{C}$ of the set thermostat temperature.

\subsection{Polycarbonate Aging Results}

Based on a maximum irradiance of $15.7 \mathrm{~kW} / \mathrm{m}^{2}$ at a distance of $65 \mathrm{~mm}$ between the LED and the bottom of the chamber, equation 1 provides a maximum irradiance of $205.2 \mathrm{~kW} / \mathrm{m}^{2}$ at the center, for a distance of $18 \mathrm{~mm}$ between sample and LED. According to Equation (2) and measurements by the IR camera, the samples placed in the center are exposed to an average irradiance of $168.6 \mathrm{~kW} / \mathrm{m}^{2}$ and an average temperature of $104{ }^{\circ} \mathrm{C}$. The samples at the rim are exposed to an average irradiance of $69.0 \mathrm{~kW} / \mathrm{m}^{2}$ and an average temperature of $62{ }^{\circ} \mathrm{C}$.

Figure 10 displays the mean value of the transmission spectra of PC samples at the center (Figure 10a) and at the rim (Figure 10b) at different aging times. It can be noticed that the decrease of transmission starts at wavelengths in the UV range. This initial decrease in transmission is due to the growth of new absorption bands in the range of $320-355 \mathrm{~nm}$ as a result of photodegradation. These absorption bands are ascribed to the photo-Fries rearrangement products L1 and L2 [11,13,14]. With prolonged aging, the decrease in transmission shifts into the visible wavelength range, which increases the absorbed amount of blue radiation by the samples, resulting in a yet stronger decrease in transmission. From this point on, the degradation of the plastic will be self-enhancing. 
(a)

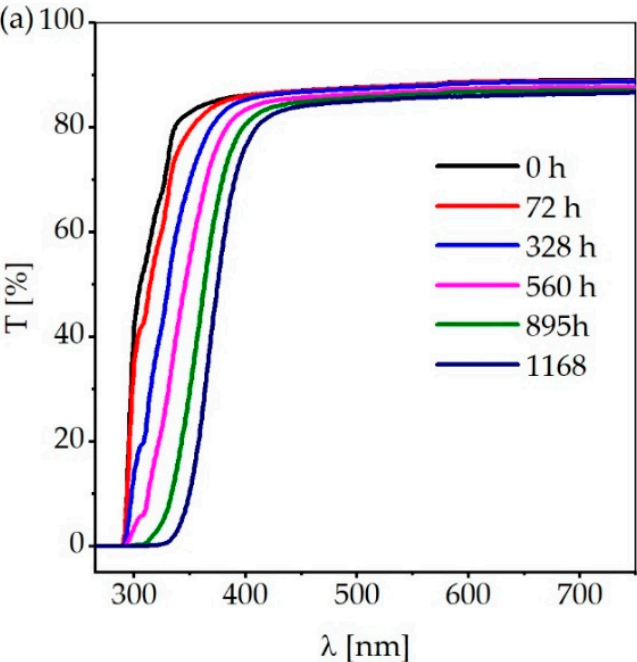

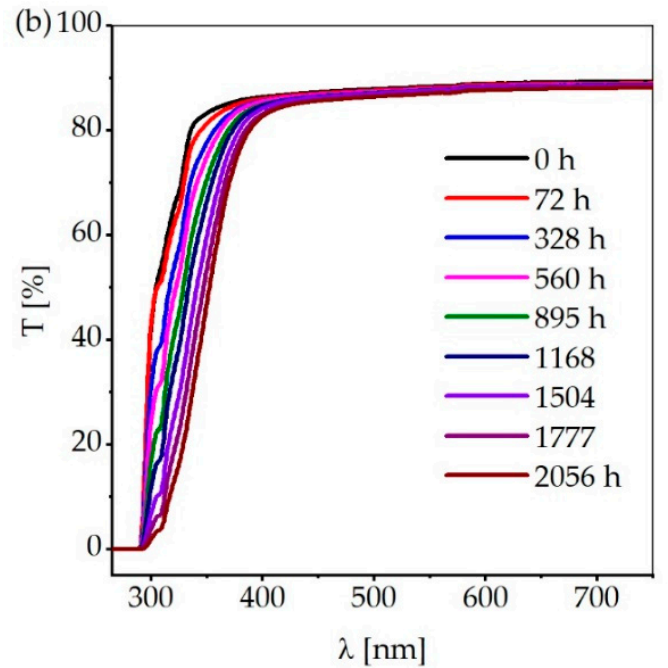

Figure 10. Mean value of the transmission spectra of PC samples at different aging times: (a) samples stored at the center of the test chamber; and (b) samples stored at the rim of the test chamber.

Within a few hours after the measurement at $987 \mathrm{~h}$, the samples stored in the center became completely black and decomposed. Figure 11 shows the mentioned sample (Figure 11a) and an PC sample before aging (Figure 11b). This sudden complete failure of the plastic can be caused by the self-amplifying effect described above and by impurities within the samples that act as a trigger or accelerator $[10,29]$. The process reveals that, once originally transparent samples start to discolor strongly, the originally selected sample temperature can no longer be ensured.

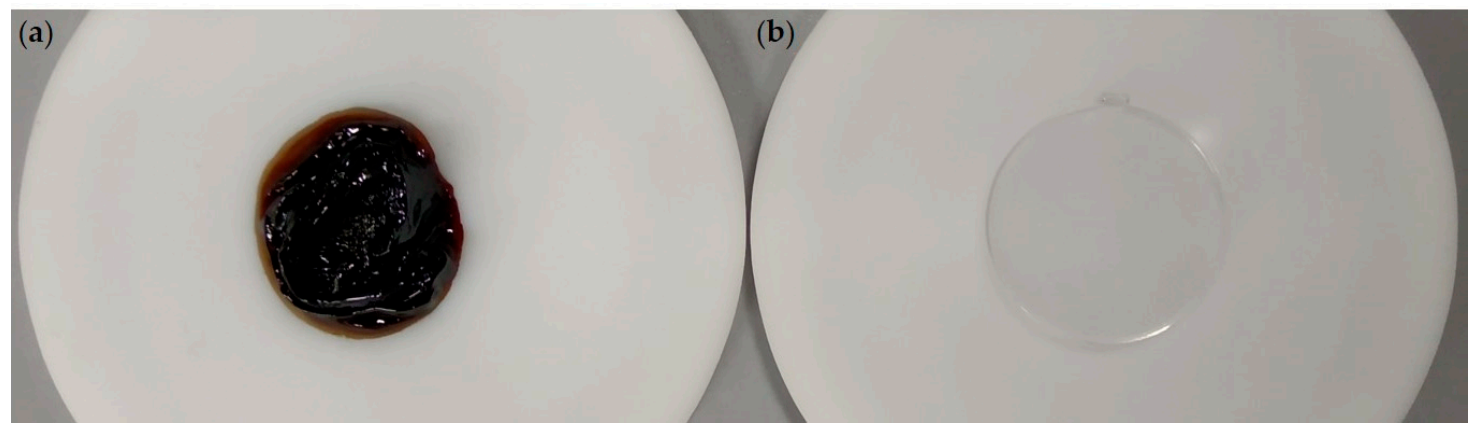

Figure 11. (a) PC sample stored in the center after complete failure after $987 \mathrm{~h}$; and (b) unaged PC sample.

To compare the samples placed in the center and at the rim, the $Y I$ calculated according to Equation (3) is shown in Figure 12a. The representation reveals that the deviation of the YI between the individual samples is relatively high. Since, according to Gandhi et al. [27], there is a close relationship between the $Y I$ and the absorbance at $360 \mathrm{~nm}$, Figure $12 \mathrm{~b}$ also shows the development of the absorbance at $360 \mathrm{~nm}$ with increasing aging time for both sample types. The progressions of the absorbance at $360 \mathrm{~nm}$ and the $Y I$ show a similar behavior, whereby the measuring accuracy of the absorbance at $360 \mathrm{~nm}$ is considerably higher. Even if the limited number of samples stored in the center of the chamber does not allow a statement about the uncertainty of the measurement, the samples in the middle show a significantly stronger exponential growth of both the YI and the absorbance at $360 \mathrm{~nm}$, compared to the samples at the edges. This verifies the mentioned self-amplifying effect of optical aging. To detect molecular changes on the surface of the PC samples as a result of photodegradation, FTIR was performed in ATR mode. The scan results of all samples (12 samples from the rim and 2 from the center) at all sampling times were averaged, normalized, and base line corrected according to 
the described algorithm. The IR spectra of the samples placed in the center and at the rim do not differ in quality. However, as expected, the changes in the samples stored in the center are more pronounced after a shorter time. Since more individual IR measurements were performed on the samples from the rim and the measurements have a higher statistical accuracy, due to the higher number of samples, these measurements are presented below.
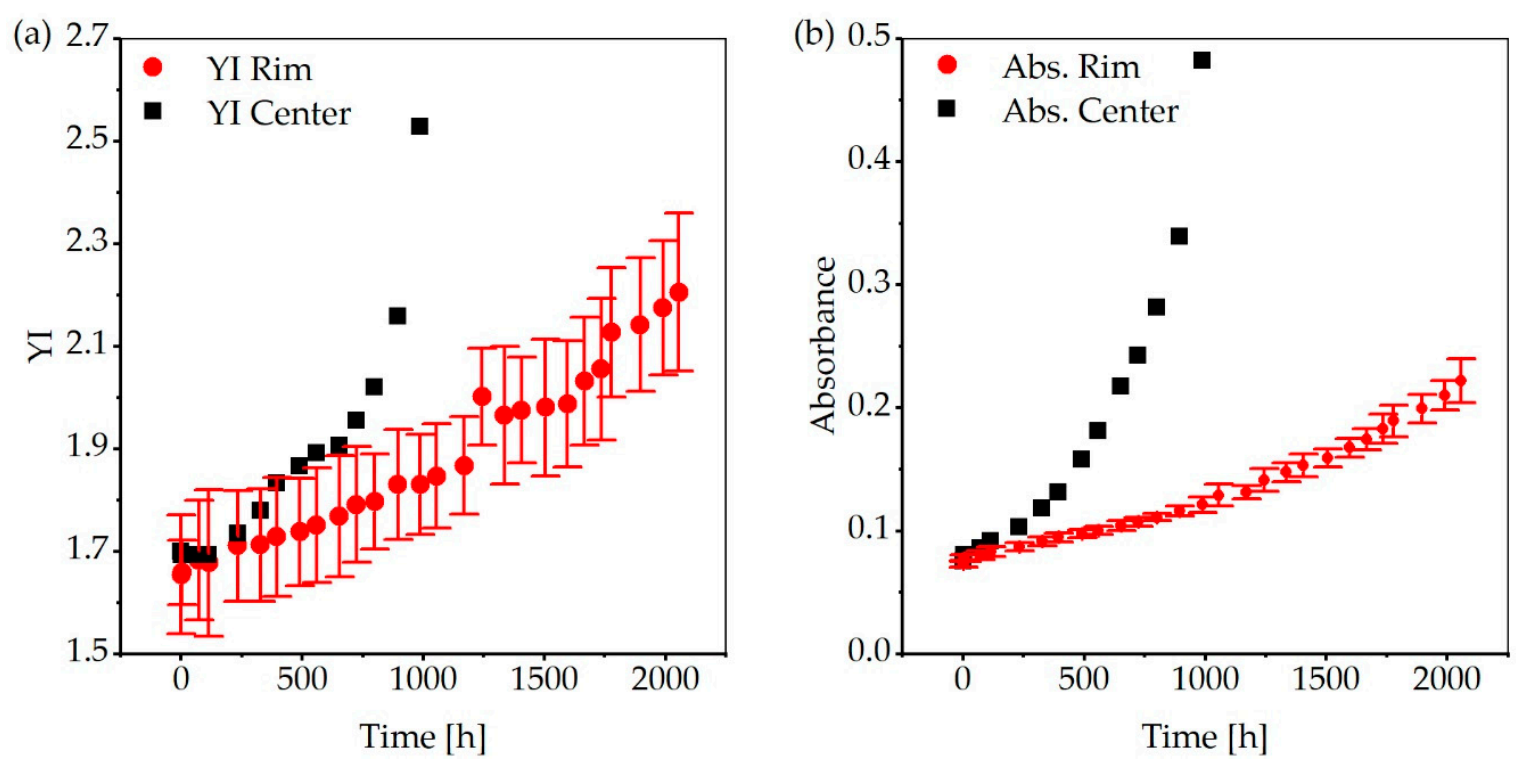

Figure 12. Progression of the $Y I$ and the absorbance at $360 \mathrm{~nm}$ with increasing aging time: (a) $Y I$; and (b) absorbance at $360 \mathrm{~nm}$. Due to the limited number of samples, no measurement accuracy could be determined for the samples in the center.

Figure 13 illustrates the IR-spectra of the carbonyl region from 1640 to $1890 \mathrm{~cm}^{-1}$ after different aging times. Outside this area, no clear changes could be observed. With increasing aging time, the increase of two distinct peaks at 1840 and $1687 \mathrm{~cm}^{-1}$ can be observed. For better illustration, Figure 13b shows the changes in the IR-spectra compared to the spectrum of the unaged samples. From this representation, a further increase in absorbance between 1718 and $1732 \mathrm{~cm}^{-1}$ can be identified. Furthermore, the carbonyl-band at $1772 \mathrm{~cm}^{-1}$ shifts to higher wavenumbers.

(a)

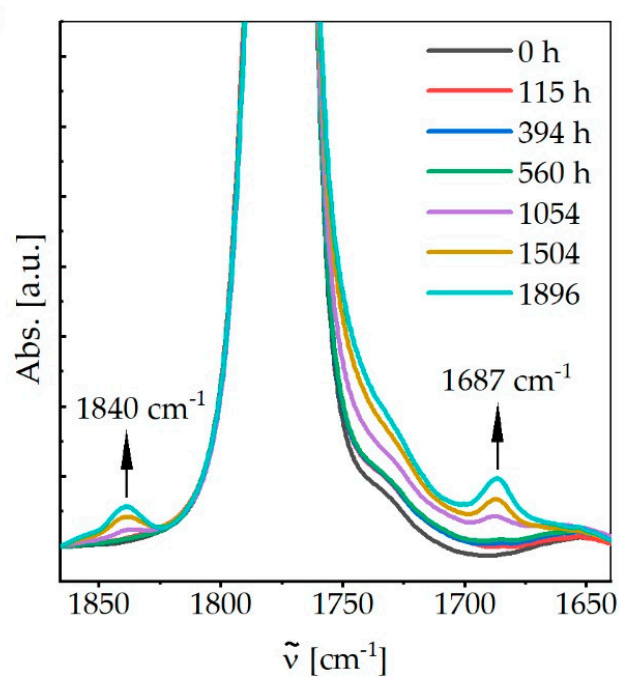

(b)

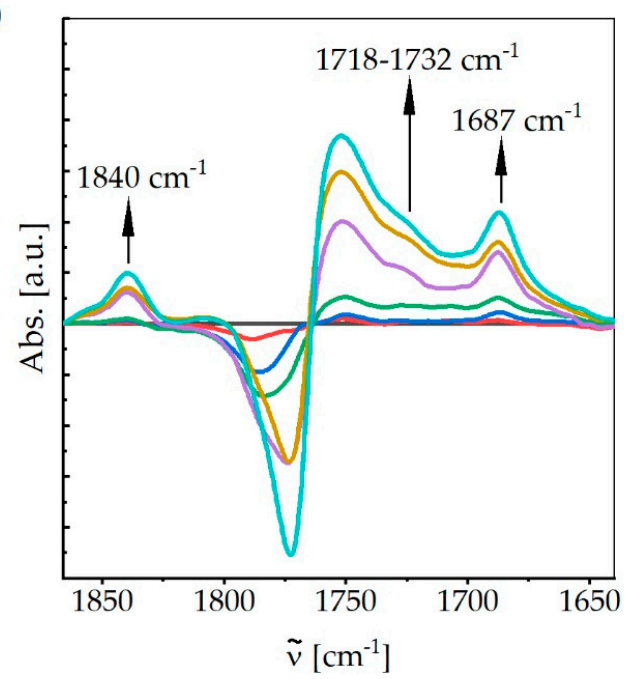

Figure 13. IR-spectra from 1640 to $1890 \mathrm{~cm}^{-1}$ after different aging times: (a) carbonyl region from 1640 to $1890 \mathrm{~cm}^{-1}$; and (b) IR-spectra compared to the spectrum of the unaged samples. 
The increase in absorbance at $1687 \mathrm{~cm}^{-1}$ can be attributed to the photo-Fries rearrangement product L1 mentioned above. An increase of the photo-Fries rearrangement product L2 at $1619 \mathrm{~cm}^{-1}$ could not be detected clearly. The absorption bands at 1840 and between 1718 and $1732 \mathrm{~cm}^{-1}$ indicate the formation of aliphatic chain acid and cyclic anhydride. These products indicate photooxidative processes $[11,13,14]$.

\section{Discussion and Outlook}

The newly developed "Monitored Liquid Thermostatted Irradiation Setup" (MLTIS) test setup provides a number of advantages over existing setups for the accelerated aging of optical materials with blue light. Samples can be aged in a wide temperature range independent of the LED power. This offers the possibility to carry out further aging experiments, e.g., at room temperature, allowing a distinction between the influence of thermal- and photodegradation. Furthermore, relevant operating parameters are monitored during the entire experiment to ensure traceable results. All relevant optical parameters of the setup were measured in advance. To determine the irradiance, a raytracing simulation was carried out using these data. Due to a flexible and modular design, samples in different geometries can be tested, while up to twelve sample chambers can be operated simultaneously and independent of each other.

To validate the test setup, polycarbonate samples with known aging behavior were aged by the MLTIS. Samples placed on the rim of the sample chamber were aged at a temperature of $62{ }^{\circ} \mathrm{C}$ $\left(104{ }^{\circ} \mathrm{C}\right.$ for samples in the center) and an irradiance of $69.0 \mathrm{~kW} / \mathrm{m}^{2}\left(168.6 \mathrm{~kW} / \mathrm{m}^{2}\right.$ for samples in the center) for a total of $1896 \mathrm{~h}$. Based on the parameters, it can be assumed that the samples are not only undergoing a photodegradation due to the high irradiation but also a thermal degradation even at the lower temperatures. UV/vis spectroscopy showed a decrease in transmission of the samples in the short wavelength range of $320-355 \mathrm{~nm}$, with increasing aging time. This decrease is attributed to known absorption bands of photo-Fries rearrangement products. Additionally, a correlation between the $Y I$ and the absorption at $360 \mathrm{~nm}$ could be shown. By IR spectroscopy, new absorption peaks at 1690, 1840, and between 1718 and $1732 \mathrm{~cm}^{-1}$ could be observed. These peaks can be assigned to the photo-Fries rearrangement product L1, as well as to the formation of aliphatic chain acid and cyclic anhydride, which indicate photooxidative processes. These results are well in agreement with known results for the photo-thermal degradation of polycarbonates, confirming the validity of the MLTIS. In summary, the novel design of this apparatus allows for reliable temperature variable testing of materials, with regard to their resistance to optical radiation. To implement a holistic and sustainable development in the field of lighting, it is important to investigate alternatives to the established optical plastics in the future. One possible alternative is the biodegradable bioplastic polylactide (PLA), which is based exclusively on renewable raw materials and has excellent optical properties in its amorphous state [30]. In the future, in-depth investigations on the resistance of PLA (e.g., in comparison to PC) to optical radiation will be carried out. In particular, due to the temperature control capabilities of the MLTIS, the PLA samples can be kept at room temperature to avoid undesirable crystallization effects during the aging process.

Author Contributions: All authors discussed and agreed upon the idea and made scientific contributions. Conceptualization, J.M. and F.W.; methodology, M.H. and J.M.; software, M.H.; validation, M.H., J.M., and F.W.; formal analysis, M.H.; investigation, M.H.; resources, J.M. and F.W.; data curation, M.H.; writing-original draft preparation, M.H.; writing—review and editing, M.H., J.M., and F.W.; visualization, M.H.; supervision, J.M. and F.W.; and project administration, J.M. and F.W. All authors have read and agreed to the published version of the manuscript.

Funding: This research was funded in part by the German Federal Ministry of Food and Agriculture, grant number 22020116.

Acknowledgments: The authors thank HELLA GmbH \& Co. KGaA for providing samples and optical equipment as well as counselling with respect to optical simulations, and furthermore Ronja Scholz ${ }^{3}$ for her contribution to discussions on the content of this research work.

Conflicts of Interest: The authors declare no conflict of interest. 


\section{Appendix A}

To determine a suitable temperature for the LED cooling, the spectrum of the LED was measured by varying the thermostat temperature. The results are illustrated in Figure A1. It can be observed that, up to the temperature of $40^{\circ} \mathrm{C}$, the LED emits a constant spectrum with a peak wavelength of $450 \mathrm{~nm}$. From $45^{\circ} \mathrm{C}$, the spectrum shifts to longer wavelengths and the maximum spectral power decreases. Therefore, to ensure that the emitted spectrum of the LED remains constant during the test period, the thermostat temperature of $34{ }^{\circ} \mathrm{C}$ was selected.

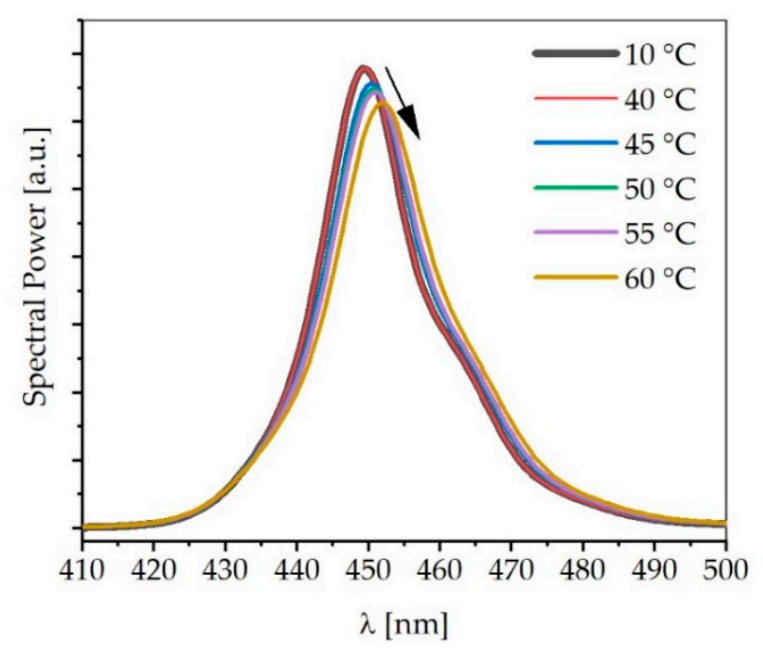

Figure A1. Plot of the LED spectrum as a function of the LED-thermostat temperature.

Table A1 shows the exact wavenumbers for the baseline correction of the recorded FTIR spectra. At these wavenumbers, the absorbance of all spectra at a certain measurement time are forced to zero.

Table A1. Exact wavenumbers for the baseline correction.

\begin{tabular}{cc}
\hline Baseline Correction Number & Wavenumber $\left(\mathbf{c m}^{\mathbf{1}}\right)$ \\
\hline 1 & 599.763 \\
2 & 689.920 \\
3 & 794.059 \\
4 & 865.413 \\
5 & 951.714 \\
6 & 1050.55 \\
7 & 1345.128 \\
8 & 1432.392 \\
9 & 1541.352 \\
10 & 1569.315 \\
11 & 1621.385 \\
12 & 1866.786 \\
13 & 1925.123 \\
14 & 1987.318 \\
15 & 2155.097 \\
16 & 2268.396 \\
17 & 2427.015 \\
18 & 2670.006 \\
19 & 3005.083 \\
20 & 3266.394 \\
21 & 3488.171 \\
22 & 3717.180 \\
23 & 4000.188 \\
\hline
\end{tabular}




\section{References}

1. Zissis, G.; Bertoldi, P. JRC Technical Reports: Status of LED-lighting world market in 2017; Joint Research Centre: Ispra, Italy, 2018.

2. Tsao, J.Y.; Wierer, J.J.; Rohwer, L.E.S.; Coltrin, M.E.; Crawford, M.H.; Simmons, J.A.; Hung, P.-C.; Saunders, H.; Sizov, D.S.; Bhat, R.; et al. Ultra-efficient Solid-State Lighting: Likely Characteristics, Economic Benefits, Technological Approaches. In III-Nitride Based Light Emitting Diodes and Applications, 2nd ed.; Seong, T.-Y., Han, J., Amano, H., Morkoç, H., Eds.; Springer: Singapore, 2017; pp. 11-28.

3. Mottier, P. LEDs for Lighting Applications; ISTE Ltd.: London, UK, 2010.

4. Winkler, H.; Bodrogi, P.; Trinh, Q.; Khanh, T.Q. LED Lighting. Technology and Perception; Wiley-VCH: Weinheim, Germany, 2015.

5. Baer, R.; Barfuß, M.; Seifert, D. Beleuchtungstechnik, 4th ed.; Huss-Medien GmbH: Berlin, Germany, 2016.

6. Mishra, M. Handbook of Vinyl Polymers. Radical Polymerization, Process, and Technology, 2nd ed.; CRC Press: Hoboken, NJ, USA, 2008.

7. Khanh, T.Q. Proceedings of the 11th International Symposium on Automotive Lighting; Herbert Utz Verlag: München, Germany, 2015.

8. Žukauskas, A.; Shur, M.; Gaska, R. Introduction to solid-state lighting; Wiley: New York, NY, USA, 2002.

9. Meyer, J.; Tappe, F. Photoluminescent Materials for Solid-State Lighting: State of the Art and Future Challenges. Adv. Opt. Mater. 2015, 3, 424-430. [CrossRef]

10. Ehrenstein, G.W.; Pongratz, S. Beständigkeit von Kunststoffen; Hanser: München, Germany, 2007.

11. Rivaton, A. Recent advances in bisphenol-A polycarbonate photodegradation. Polym. Degrad. Stab. 1995, 49, 163-179. [CrossRef]

12. Pickett, J.E. Influence of photo-Fries reaction products on the photodegradation of bisphenol-A polycarbonate. Polym. Degrad. Stab. 2011, 96, 2253-2265. [CrossRef]

13. Rivaton, A.; Sallet, D.; Lemaire, J. The photochemistry of bisphenol-A polycarbonate reconsidered. Polym. Photochem. 1983, 3, 463-481. [CrossRef]

14. Rivaton, A.; Sallet, D.; Lemaire, J. The photo-chemistry of bisphenol-A polycarbonate reconsidered: Part 2-FTIR analysis of the solid-state photo-chemistry in 'dry' conditions. Polym. Degrad. Stab. 1986, 14, 1-22. [CrossRef]

15. Sikora, A.; Tomczuk, K. Impact of the LED-based light source working regime on the degradation of polymethyl methacrylate. Lighting Res. Technol. 2020, 52, 94-105. [CrossRef]

16. Gardette, M.; Perthue, A.; Gardette, J.-L.; Janecska, T.; Földes, E.; Pukánszky, B.; Therias, S. Photo- and thermal-oxidation of polyethylene: Comparison of mechanisms and influence of unsaturation content. Polym. Degrad. Stab. 2013, 98, 2383-2390. [CrossRef]

17. Yazdan Mehr, M.; Toroghinejad, M.R.; Karimzadeh, F.; van Driel, W.D.; Zhang, G.Q. Reliability and diffusion-controlled through thickness oxidation of optical materials in LED-based products. Microelectron. Reliab. 2017, 78, 143-147. [CrossRef]

18. Yazdan Mehr, M.; van Driel, W.D.; Jansen, K.M.B.; Deeben, P.; Zhang, G.Q. Lifetime assessment of Bisphenol-A Polycarbonate (BPA-PC) plastic lens, used in LED-based products. Microelectron. Reliab. 2014, 54, 138-142. [CrossRef]

19. Yazdan Mehr, M.; van Driel, W.D.; Koh, S.; Zhang, G.Q. Reliability and optical properties of LED lens plates under high temperature stress. Microelectron. Reliab. 2014, 54, 2440-2447. [CrossRef]

20. Yazdan Mehr, M. Organic materials degradation in solid state lighting applications. Ph.D. Thesis, Technical University of Delft, Delft, The Netherlands, November 2015.

21. Yazdan Mehr, M.; van Driel, W.D.; Zhang, G.Q. Reliability and Lifetime Assessment of Optical Materials in LED-Based Products. In Solid State Lighting Reliability: Components to Systems; van Driel, W.D., Fan, X., Zhang, G.Q., Eds.; Springer: Cham, Switzerland, 2018; pp. 115-139.

22. Yazdan Mehr, M.; van Driel, W.D.; Zhang, G.Q. Progress in Understanding Color Maintenance in Solid-State Lighting Systems. Engineering 2015, 1, 170-178. [CrossRef]

23. Lu, G.; Yazdan Mehr, M.; van Driel, W.D.; Fan, X.; Fan, J.; Jansen, K.M.B.; Zhang, G.Q. Color Shift Investigations for LED Secondary Optical Designs: Comparison between BPA-PC and PMMA. Opt. Mater. 2015, 45, 37-41. [CrossRef] 
24. Yazdan Mehr, M.; Toroghinejad, M.R.; Karimzadeh, F.; van Driel, W.D.; Zhang, G.Q. A review on discoloration and high accelerated testing of optical materials in LED based-products. Microelectron. Reliab. 2018, 81, 136-142. [CrossRef]

25. Yazdan Mehr, M.; van Driel, W.D.; Jansen, K.M.B.; Deeben, P.; Boutelje, M.; Zhang, G.Q. Photodegradation of bisphenol A polycarbonate under blue light radiation and its effect on optical properties. Opt. Mater. 2013, 35, 504-508. [CrossRef]

26. Yazdan Mehr, M.; van Driel, W.D.; Udono, H.; Zhang, G.Q. Surface aspects of discolouration in Bisphenol A Polycarbonate (BPA-PC), used as lens in LED-based products. Opt. Mater. 2014, 37, 155-159. [CrossRef]

27. Gandhi, K.; Hein, C.L.; van Heerbeek, R.; Pickett, J.E. Acceleration parameters for polycarbonate under blue LED photo-thermal aging conditions. Polym. Degrad. Stab. 2019, 164, 69-74. [CrossRef]

28. DIN6167, D.I. Beschreibung der Vergilbung von nahezu weißen oder nahezu farblosen Materialien; Deutsches Institut für Normung e.V.: Berlin, Germany, 1980.

29. Rabek, J.F. Polymer Photodegradation. Mechanisms and Experimental Methods; Springer Science \& Business Media: Dordrecht, The Netherlands, 2012.

30. Baltscheit, J.; Schmidt, N.; Schröder, F.; Meyer, J. Investigations on the aging behavior of transparent bioplastics for optical applications. InfoMat 2020, 2, 424-433. [CrossRef]

(C) 2020 by the authors. Licensee MDPI, Basel, Switzerland. This article is an open access article distributed under the terms and conditions of the Creative Commons Attribution (CC BY) license (http://creativecommons.org/licenses/by/4.0/). 